\title{
SEXUAL ASSAULT: PATTERN COMPLICATIONS AMONG CASES MANAGED AND RELATED UNIVERSITY SPECIALIZED HOSPITAL
}

\author{
Demisew Amenu', Desta Hiko ${ }^{2}$
}

\section{ABSTRACT}

BACKGROUND: Sexual assault affects one out of every five women, and it is a substantial public health and human rights problem in developing countries including Ethiopia. There has not been a study which documented the extent of the problem in the study area; hence the objective of this study was to assess the pattern of sexual assault and related complications in cases which were treated at Jimma University Specialized Hospital from November 1, 2011 -October 31, 2012.

METHODS: A hospital based cross-sectional descriptive study was conducted with the aim of assessing sexual assault patterns and related complications on 99 sexual assault cases which were managed at the Gynecology Out-patient Department of the Hospital. Data on circumstances of sexual assault, survivor specific demographic characteristics and information on complications and interventions provided were collected by trained third year residents in obstetrics and gynecology using pretested questionnaire after respondent consent was taken. The collected data was cleaned, edited, fed into computer and analyzed using SPSS for windows version 16.0.

RESULTS: The mean ( $\pm S D)$ of the survivors' age was $14( \pm 5)$ years; $57.5 \%$ of the survivors were children and $68.7 \%$ were from rural areas. Three percent of the clients visited the Gynecology Outpatient Department for sexual assault where rape accounted for $78.8 \%$. The majority (76.8\%) of the assailants was known to the survivors, $91 \%$ were assaulted by one assailant and $5.1 \%$ of the rape cases were gang rape. The mean time of presentation after sexual assault to the hospital was 15 days. Survivors had pregnancy test, HIV test and screening for sexually transmitted infections in $76.8 \%$, 99\%, 93\% respectively of which $17.1 \%, 5.1 \%, 14.1 \%$ tested positive for pregnancy, HIV, and some STIs respectively. All HIV positive survivors were children under fifteen years of age. Forty percent of the survivors were provided with emergency contraception. In addition, $60.5 \%, 63 \%$, and $91.9 \%$ of them were provided with post-exposure prophylaxis for HIV, STIs prophylaxis and were given counseling respectively.

CONCLUSION: It has been revealed that sexual assault is a major problem of women and children of less than fifteen years. There were gaps in providing and receiving packages of care and justice system to protect survivors indicating the needs for community intervention and providing quality of care by health care staff.

KEYWORDS: Sexual assault, assailant, survivors, rape, attempted rape, sexual abuse

DOI: http://dx.doi.org/10.4314/ejhs.v24i1.1

\section{INTRODUCTION}

Sexual assault is a major form of sexual violence affecting women. It includes, rape, attempted rape, sexual abuse and sexual exploitation (1). Exposure to sexual assault significantly increases girls' and women's chances of early sexual debut, experiencing forced sex, engaging in transactional

\footnotetext{
1Department of Gynecology and Obstetrics, Jimma University, Jimma, Ethiopia

${ }^{2}$ Department of Epidemiology, Jimma University, Jimma, Ethiopia

Corresponding Author: Demisew Amenu, Email: demisew.amenu@ju.ed.et
} 
sex, and non-use of condoms (2, 3, 4). Sexual violence can adversely affect the physical and mental health of survivors (5). It is a considerable public health and human rights problem around the world including Ethiopia because of the associated morbidity and mortality.

It is estimated that up to six out of every ten women in the world experience physical or sexual violence in their lifetime and one woman of every five has suffered an attempted or completed rape by an intimate partner during her lifetime $(6,7)$.

A limited but growing body of evidence suggests that sexual violence affects up to one third of the women population during their lifetime. Sexual assault is underreported, and its wide prevalence in estimated lifetime prevalence reflects the method of data collection, with lower rates $(12-20 \%)$ reported in persons presenting for medical care and higher rates (20-30\%) reported in community surveys. And, $50-80 \%$ of sexual assaults are committed by a person known to the survivor and less than one fourth of the survivors report sexual assault to the police (8).

Studies have found that $7-36 \%$ of women report having experienced some type of sexual abuse in childhood, that 6-59\% of women report having been sexually assaulted by an intimate partner after the age of 15 and $5-10 \%$ male children suffer from sexual violence/abuse $(9,10)$.

In World Health Organization (WHO) multicountry study, the study done in an Ethiopian province showed that $54 \%$ of women reported physical or sexual violence, or both and $31 \%$ experienced sexual violence only $(11,12)$.

A study conducted in two hospitals in Addis Ababa (Tikur Anbessa and St.Paul's) which assessed 170 cases of sexual assault revealed that majority were children of less than fifteen years and they were less educated. Seventy-three $(42.9 \%)$ cases indicated that the offenders were strangers; $11(6.5 \%)$ were incest and $46(27.1 \%)$ were neighbors. There were minor Physical injuries and $11(6.5 \%)$ were pregnant at the time of reporting. There was a significant delay in reporting to the health institutions and the police with the mean delay of 15.6 and 18.4 days respectively (13). In the other study, the average time for reporting was 34.6 days to health institutions and the police, the range being 2 hours to 2 years (14), as compared to the median time from onset of assault to presentation of 16 hours in
USA. Sexual assault by a known assailant was associated with delayed presentation (15).

The World Health Organization identifies traditional gender norms that encourage male superiority and entitlement, social norms that tolerate or justify violence against women, weak community sanctions against perpetrators, poverty and high levels of crime and conflict in society as evidence-supported risk factors (16).

Research on sexual assault against women shows an increased risk of current physical or sexual violence among women of a younger age, especially those aged 15 to 19 , living in single parent households, grandparent headed households, and women who are separated or divorced. Approximately 50\% of sexual assault perpetrators consume alcohol prior to or during the assault (17).

A prospective study conducted at Mulago Hospital, Kampala, to determine the clinical presentation and management of alleged sexually assaulted females showed that $72 \%$ of the survivors were children of below 12 years. Fifty percent of the assault occurred at the assailant's home. The majority $(79.3 \%)$ of the victims knew the assailant, and cases of gang rape were only $6.9 \%$. The injuries sustained were extra genital (19.0\%), genital (75.4\%) and both $19 \%$. Emotional/psychological disturbance was present in $22.4 \%$ of the patients. All cases received counseling and prophylactic treatment for sexually transmitted infections. Those in reproductive age group were offered emergency contraception (18).

A Study done at the Red Cross War Memorial Children's Hospital, Cape Town, to ascertain the incidence of child rape revealed that survivors ranged from 10 months to 13 years (mean 5.8 years). Seventy-nine percent of the assaults were caused by a perpetrator known to the victim. All but 5 perpetrators were males. Fiftyeight percent of rapes occurred in the patient's own home or that of a friend or relative (19).

Survivors of sexual abuse may have physical injuries that require immediate attention. Lifethreatening injuries take priority over other components of medical management; therefore, health care providers need to collect and conserve evidence for forensic analysis. The components of the clinical evaluation act as a vital link between health care and the judicial system (20). 
Pregnancy resulting from rape is generally unwanted and traumatic. To prevent this, Emergency Contraception (EC) should be available to all female survivors of rape who are of reproductive age and who show signs of secondary sexual development $(20,21)$.

A study in Zambia found out that the majority $(91 \%)$ of sexual abuse survivors seek support from the police before seeking healthcare. This reflects widespread beliefs that sexual assault is primarily a criminal rather than a health concern. Although $82 \%$ of all survivors arrived at health facilities within EC's window of effectiveness (within 120 hours), only $37 \%$ received EC from hospital staff. Even fewer, $24 \%$, received post-exposure HIV prophylaxis (22).

However, there is a challenge of emergency contraception provision at health facilities to survivors of sexual assault in Ethiopia. A study conducted to assess EC provision for sexually assaulted women at health facilities in Addis Ababa, Ethiopia, showed that out of the 384 cases included in the study, $28.4 \%$ were provided with EC. Fifty-five percent of the cases were evaluated within the first five days of the incident. Thirteen percent of the survivors were pregnant by the time they were examined (14).

Survivors of sexual abuse are vulnerable to a number of sexually transmitted infections (STIs) (23). Medical management protocols in high STIprevalence settings advise that STI prophylaxis be offered to all rape survivors presenting within the first 24 hours (24).

The risk of sero-conversion following rape is likely to be higher than following consensual sex, given the increased physical trauma, especially in children. To combat this post-exposure Prophylaxis to HIV negative persons presenting within 72 hours is recommended (25).

In a 5 year retrospective study done to assess the incidence of HIV infection among survivors of sexual assaults in Transkei, Eastern Cape, South Africa, 443 (53.3\%) were children under 15 years of age, $114(13.7 \%)$ were tested positive for HIV, and $23(2.7 \%)$ were children of less than 15 years (26).

Emotional consequences expressed in the 'rape trauma syndrome' are often longer lasting and more difficult to diagnose. Therefore, psychological counseling of rape survivors has been identified as a key for speeding the recovery process. However, in many resource-poor settings, formal counseling services are not well or widely established (27).

Forensic evidence is needed to confirm the occurrence of sexual assault and to prove or disprove a link between the alleged perpetrator and the assault. This includes at least vaginal swab for spermatozoa, provider initiated HIV testing and counseling, baseline pregnancy test and screening for sexually transmissible infections (24, 28).

Although there are some community based studies done covering small areas previously in Jimma Zone, there is no study conducted in Jimma University Specialized Hospital (JUSH) that has investigated the magnitude of the problem. This study was, therefore, aimed at assessing the pattern of sexual assault, associated risk factors, complications and outcomes.

\section{METHODS AND PARTICIPANTS}

The study was conducted in Oromia Region, Jimma Zone, Jimma Town, at Jimma University Specialized Hospital, Obstetrics and Gynecology Department, Gynecology Outpatient department from November 1, 2011-October 31, 2012. The hospital is one of the oldest teaching hospitals in the country. It provides services to people living in Jimma Zone and serves as a referral hospital in South-West Ethiopia. It is also serving as a clinical postgraduate specialty teaching hospital for Obstetrics and Gynecology, Internal Medicine, Pediatrics and Child Health since 2005 and for Ophthalmology and Surgery since 2007. The Department of Obstetrics and Gynecology has one gynecology ward, one maternity and labor ward, one gynecology OPD, one antenatal care clinic and one family planning clinic (JUSH archive).

A hospital based cross-sectional descriptive study design was used to assess all sexual assault cases and related complications among gynecologic visits that were managed at Gynecology Outpatient Department (OPD) during the study period.

A structured interviewer administered English version pretested data collection format was used to collect data. Data collectors translated the English version of the format into the local language to capture data from the study participants and their charts. Five third year 
residents in obstetrics/gynecology were trained on how to approach survivors of sexual assault, do proper physical examination, and obtain samples for forensic tests: pregnancy test, HIV test, screening test for STIs and sperm analysis when necessary and treat cases through demonstration of few cases at OPD. Data were collected by identifying clients by their card number and checked daily for completeness.

Finally, the collected data were cleaned, fed to computer and analyzed using SPSS version 16.0 for windows, and interpretation, discussion and recommendation were made based on the findings.

An official letter was obtained from the Ethical Review Board of Jimma University to conduct this research and get consent from each patient. The patients were told about the objectives and benefits of the study and after having verbal consent from the survivors, data collectors took history of the patients, patient-specific demographic characteristics and information on circumstance of sexual assault from physical findings and laboratory results. The outcome of this study has been communicated to the Department of Obstetrics and Gynecology and to the clinical Director of Jimma University Specialized Hospital.

In this research, the following operational definitions were used (1):

Sexual violence: any sexual act, attempt to obtain a sexual act, unwanted sexual comments or advances, or acts to traffic a person's sexuality, using coercion, threats of harm or physical force, by any person regardless of relationship to the survivor, in any setting, including but not limited to home and work environments.

Rape: an act of non-consensual sexual intercourse including the invasion of any part of the body with a sexual organ and/or the invasion of the genital or anal opening with any object or body part.

Attempted rape: Efforts to rape someone which do not result in penetration

Sexual abuse: other non-consensual sexual acts, not including rape or attempted rape and includes acts performed on a minor.

Sexual assault: a major form of sexual violence which includes at least rape, attempted rape and sexual abuse.

Perpetrator/assailant: a male or female, group or institution that inflicts, supports, or condones violence or other abuses against a person or group of persons

Survivor/victim: a person who has lived through an incident of sexual assault. Survivor is a more preferred term as it has a positive connotation.

\section{RESULTS}

Among the total of 105 survivors of sexual assault who visited Jimma University Specialized Hospital during the study period, 6 were excluded as their data was incomplete and the remaining 99 form the basis of our analysis. The age of the survivors ranged from 3 to 30 years with the mean age of $14( \pm 5)$ years. Seventy-seven percent of them were in the age range 10 to 20 years, 57 $(57.5 \%)$ were children under fifteen years of which $6(6.1 \%)$ were less or equal 5 years. All survivors of sexual assault were females and the majority of the survivors were from rural areas, Muslims, Oromos, students, grades 1-8 and of very low monthly family or personal income (Table 1).

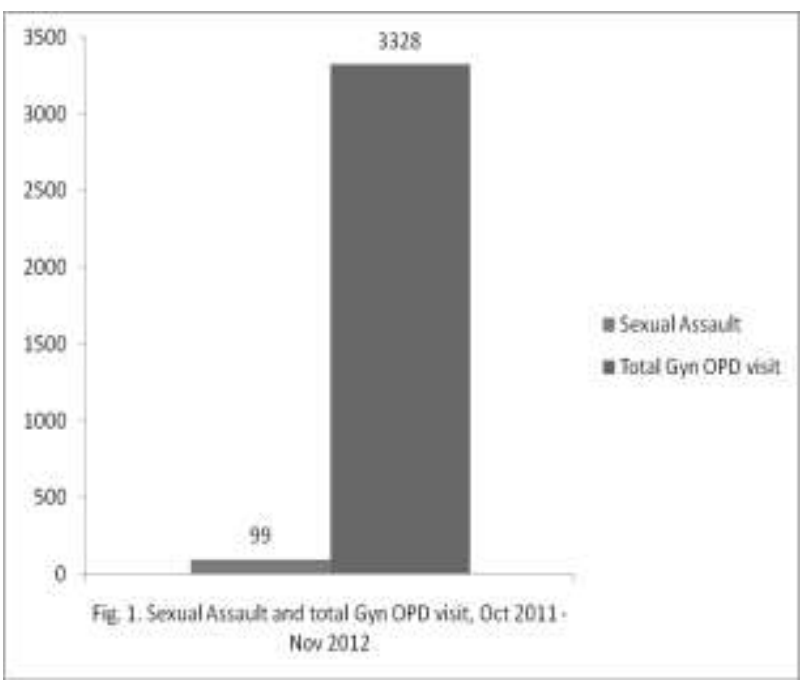

Sexual assault accounted for 3\% of gynecology OPD visits in the hospital during the study period (Fig 1). Concerning the circumstance of sexual assault, from $78(78.8 \%)$ rape cases, $42(42.4 \%)$ were children of fifteen years or below and alcohol was used to control the survivors in $4 \%$ of the cases. Seventy one percent were assaulted during the day and all assailants were civilians. 
Table 1: Demographic Characteristics of survivors of sexual assault managed in JUSH, Oct 2011-Nove 2012.

\begin{tabular}{|c|c|c|c|}
\hline Variables & & Number (99) & Percentage \\
\hline \multirow[t]{5}{*}{ Age in years } & $\leq 5$ & 6 & 6.1 \\
\hline & $\overline{6}-10$ & 15 & 15.2 \\
\hline & $11-15$ & 36 & 36.4 \\
\hline & $16-20$ & 40 & 40.4 \\
\hline & $\geq 21$ & 2 & 2.0 \\
\hline \multirow[t]{2}{*}{ Address } & Urban & 31 & 31.3 \\
\hline & Rural & 68 & 68.7 \\
\hline \multirow[t]{6}{*}{ Ethnicity } & Oromo & 69 & 69.7 \\
\hline & Amhara & 16 & 16.2 \\
\hline & Tgrie & 1 & 1.0 \\
\hline & Guragie & 7 & 7.1 \\
\hline & Dawuro & 4 & 4.0 \\
\hline & Others & 2 & 2.0 \\
\hline \multirow[t]{5}{*}{ Occupation } & Students & 72 & 72.7 \\
\hline & Maids & 4 & 4.0 \\
\hline & Dependent & 14 & 14.1 \\
\hline & Preschool & 5 & 5.1 \\
\hline & Others & 4 & 4.0 \\
\hline \multirow[t]{5}{*}{ Educational status } & illiterate & 16 & 16.2 \\
\hline & kindergarten & 1 & 1.0 \\
\hline & preschool & 8 & 8.1 \\
\hline & grade $1-8$ & 68 & 68.7 \\
\hline & grade $9-12$ & 6 & 6.1 \\
\hline \multirow[t]{3}{*}{ Religion } & Orthodox Christian & 30 & 30.3 \\
\hline & Protestant & 22 & 22.2 \\
\hline & Muslim & 47 & 47.5 \\
\hline \multirow{3}{*}{$\begin{array}{l}\text { Personal/family } \\
\text { income in Birr }\end{array}$} & $\leq 500$ & 43 & 43.4 \\
\hline & $600-1000$ & 36 & 36.4 \\
\hline & $\geq 1001$ & 20 & 20.2 \\
\hline \multirow{4}{*}{$\begin{array}{l}\text { Current survivors } \\
\text { relationship status }\end{array}$} & Married and or steady boy friend & 3 & 3.0 \\
\hline & No male partner & 10 & 10.1 \\
\hline & Living with mother and father & 69 & 69.7 \\
\hline & Living with relatives & 17 & 17.2 \\
\hline
\end{tabular}

The majority of the assailants were known to the survivors, $76(76.8 \%)$, most of the assaults were committed in assailant's or survivors' home, 56 $(56.5 \%)$ and $69(69.7 \%)$ of the survivors were living with their mothers and fathers. Ninety one percent of the survivors were assaulted by one assailant and $5(5.1 \%)$ of the cases was gang rape.
Seventy percent of the survivors were assaulted once while $8(8.1 \%)$ were assaulted for four and more episodes. In seventy-six percent of cases, the police station was the first institution to which the crime of sexual assault was reported, and 48 $(48.5 \%)$ were taken to the hospital by their family, but $40(40.5 \%)$ by the police (Table 2$)$. 
Table 2: Circumstances of survivors of sexual assault managed in JUSH, Oct 2011-Nov 2012.

\begin{tabular}{|c|c|c|c|}
\hline variables & & Number (99) & Percentage \\
\hline \multirow[t]{3}{*}{ Type of sexual assault } & Rape & 78 & 78.8 \\
\hline & attempted rape & 14 & 14.1 \\
\hline & sexual abuse & 7 & 7.1 \\
\hline \multirow{4}{*}{$\begin{array}{l}\text { Brought to the hospital } \\
\text { by }\end{array}$} & Her own & 7 & 7.1 \\
\hline & Family & 48 & 48.5 \\
\hline & Police & 40 & 40.4 \\
\hline & Others & 4 & 4.0 \\
\hline \multirow[t]{2}{*}{ Alcohol use by assailant } & Yes & 4 & 4.0 \\
\hline & No & 95 & 96.0 \\
\hline \multirow[t]{2}{*}{ Time of assault } & Day & 70 & 70.7 \\
\hline & Night & 29 & 29.3 \\
\hline \multirow[t]{3}{*}{ Number of assailants } & 1 & 90 & 90.9 \\
\hline & 2 & 4 & 4.0 \\
\hline & $\geq 3$ & 5 & 5.1 \\
\hline \multirow{4}{*}{$\begin{array}{l}\text { Number of times } \\
\text { assaulted }\end{array}$} & 1 & 69 & 69.7 \\
\hline & 2 & 12 & 12.1 \\
\hline & 3 & 10 & 10.1 \\
\hline & $\geq 4$ & 8 & 8.1 \\
\hline \multirow{6}{*}{$\begin{array}{l}\text { Perpetrators relationship } \\
\text { with survivors }\end{array}$} & Stranger & 24 & 24.2 \\
\hline & Acquaintance & 41 & 41.4 \\
\hline & Employer & 1 & 1.0 \\
\hline & Neighbor & 22 & 22.2 \\
\hline & Relative & 5 & 5.1 \\
\hline & Others & 6 & 6.1 \\
\hline \multirow[t]{6}{*}{ Place of assault } & Own home & 23 & 23.2 \\
\hline & Assailant's home & 33 & 33.3 \\
\hline & School & 3 & 3.0 \\
\hline & Garden & 14 & 14.1 \\
\hline & Bush & 20 & 20.2 \\
\hline & Others ${ }^{*}$ & 6 & 6.1 \\
\hline \multirow{3}{*}{$\begin{array}{l}\text { First institution reported } \\
\text { to }\end{array}$} & Health institution & 22 & 22.2 \\
\hline & Police & 75 & 75.8 \\
\hline & Others & 2 & 2.0 \\
\hline
\end{tabular}

* survivor's friend home $=3$, Office $=1$, assailant' friend home by a boyfriend $=2$

The first time of presentation after the incident of sexual assault to the hospital ranges from 1 day to 240 days with the mean time of 15 days. With respect to the lesions associated with sexual assault: $80(80.8 \%)$ had genital lesions of which hymenal tear accounts for $75(75.8 \%)$, perineal tear $3(3.0 \%)$, rectovaginal fistula 1 (1.0\%). Eighteen percent of those with hymenal tear had associated non-genital lesions, and of these, one had sustained right humeral shaft fracture. Twenty-seven percent had associated mild to severe non-genital lesions and bruise is the commonest. Thirteen percent of the survivors had neither genital lesions nor extra genital lesions (Table 3). 
Table 3: The first time of presentation of survivors of sexual assault and related injuries managed in JUSH, Oct 2011Nov 2012.

\begin{tabular}{llll}
\hline Variables & & Number (99) & Percentage \\
\hline Time of presentation to the & 1 day & 21 & 21.2 \\
Hospital after assault & 2-3 days & 17 & 17.2 \\
& 4-5 days & 16 & 16.2 \\
& $\geq 6$ days & 45 & 45.5 \\
\hline Genital injuries & Hymenal tear & 75 & 75.8 \\
& Perineal tear & 3 & 3.0 \\
& Rectovaginal fistula & 1 & 1.0 \\
& Other genital lesions & 1 & 1.0 \\
& None & 19 & 19.2 \\
\hline Non-genital injuries & Bruise & 9 & 9.1 \\
& Abrasion & 7 & 7.1 \\
& Echymoses & 4 & 4.0 \\
& Laceration & 6 & 6.1 \\
& Fracture & 1 & 1.0 \\
& None & 72 & 72.7 \\
\hline
\end{tabular}

Of all the survivors of sexual assault, $76(76.8 \%)$, 98 (99\%), 92 (93\%) had underwent pregnancy test, HIV test, screening for one or more sexually transmitted infections (STIs) respectively. The test results were positive at the time of evaluation for pregnancy, HIV, and some STIs in $13(17.1 \%), 5$
$(5.1 \%), 13(14.1 \%)$ respectively. All survivors with positive result for HIV were under fifteen years of age. Vaginal swab was taken for sperm analysis in $25(25.2 \%)$ of the cases and found to be positive for motile and dead sperm in $11(44 \%)$ (Table 4).

Table 4: Laboratory tests performed and medico-legal issues of survivors of sexual assault managed in JUSH, Oct 2011- Nov 2012.

\begin{tabular}{|c|c|c|c|}
\hline Variables & & Number (99) & Percent \\
\hline \multirow[t]{3}{*}{ Pregnancy test } & Positive & 13 & 13.1 \\
\hline & Negative & 63 & 63.6 \\
\hline & Not done & 23 & 23.2 \\
\hline \multirow[t]{4}{*}{ Screening done for STIs } & VDRL & 84 & 84.8 \\
\hline & VDRL and Gram stain & 2 & 2.0 \\
\hline & VDRL and HBSAg & 6 & 6.1 \\
\hline & Nothing done & 7 & 7.1 \\
\hline \multirow[t]{3}{*}{ HIV test } & Positive & 5 & 5.1 \\
\hline & Negative & 93 & 93.9 \\
\hline & Not done & 1 & 1.0 \\
\hline \multirow{4}{*}{$\begin{array}{l}\text { Vaginal swab for sperm } \\
\text { analysis }\end{array}$} & Motile sperm detected & 4 & 4.0 \\
\hline & Dead sperm detected & 7 & 7.1 \\
\hline & Negative & 14 & 14.1 \\
\hline & Not done & 74 & 74.8 \\
\hline \multirow{5}{*}{$\begin{array}{l}\text { Screening test positive for } \\
\text { STI }\end{array}$} & VDRL & 3 & 3.0 \\
\hline & Gram stain & 3 & 3.0 \\
\hline & Saline mount & 2 & 2.0 \\
\hline & HBSAg & 5 & 5.1 \\
\hline & None & 86 & 86.9 \\
\hline \multirow{4}{*}{$\begin{array}{l}\text { Medico-legal certificate } \\
\text { given to }\end{array}$} & Police & 78 & 78.8 \\
\hline & Survivor & 4 & 4.0 \\
\hline & Family & 12 & 12.1 \\
\hline & Not given & 5 & 5.1 \\
\hline \multirow{4}{*}{$\begin{array}{l}\text { Legal measures taken } \\
\text { against perpetrators }\end{array}$} & Under investigation & 78 & 78.8 \\
\hline & Pending trail & 3 & 3.0 \\
\hline & Denied, pending trail & 10 & 10.1 \\
\hline & No information & 8 & 8.1 \\
\hline
\end{tabular}


Out of $54(54.5 \%)$ survivors of sexual assault presented within the first five days of assault, 42 $(77.8 \%)$ were potentially eligible for emergency contraception and $17(40.5 \%)$ were provided with the service. Sixty point five percent of the survivors presented within three days were provided with post exposure prophylaxis for HIV, $63 \%$ of those presented within 24 hours were provided with STIs prophylaxis and 91 (91.9\%) were given counseling (Table 5,6).

Table 5: Provision of interventions by the time of presentation to the hospital in survivors of sexual assault managed in JUSH, Oct 2011- Nov 2012.

\begin{tabular}{|c|c|c|c|c|c|c|}
\hline \multirow[t]{2}{*}{ Variables } & & \multicolumn{4}{|c|}{ The first time of presentation to the hospital after assault } & \multirow[t]{2}{*}{ Total (99) } \\
\hline & & Day 1 & Day 2-3 & Day $4-5$ & Day $\geq 6$ & \\
\hline Provision of & Yes & $10(47.6 \%)$ & $4(23.5 \%)$ & $3(18.8 \%)$ & $0(0.0 \%)$ & $17(17.2 \%)$ \\
\hline $\begin{array}{l}\text { emergency } \\
\text { contraception }\end{array}$ & No & $11(52.4 \%)$ & $13(76.5)$ & $13(81.2 \%)$ & $45(100.0)$ & $82(82.8 \%)$ \\
\hline Provision of post & Yes & $14(66.7 \%)$ & $9(52.9 \%)$ & $1(6.2 \%)$ & $0(0.0 \%)$ & $24(24.2 \%)$ \\
\hline $\begin{array}{l}\text { exposure } \\
\text { prophylaxis }\end{array}$ & No & $7(33.3 \%)$ & $8(47.1 \%)$ & $15(93.8 \%)$ & $45(100.0)$ & $75(75.8 \%)$ \\
\hline Provision of STIs & Yes & $14(66.7 \%)$ & $9(52.9 \%)$ & $4(25.0 \%)$ & $1(2.2 \%)$ & $28(28.3 \%)$ \\
\hline prophylaxis & No & $7(33.3 \%)$ & $8(47.1 \%)$ & $12(75.0 \%)$ & $44(97.8 \%)$ & $71(71.7 \%)$ \\
\hline
\end{tabular}

Table 6: Provision of emergency contraception by age category of survivors of sexual assault managed in JUSH, Oct 2011- Nov 2012

\begin{tabular}{l|llll}
\hline Variable & \multicolumn{5}{|c}{$\begin{array}{l}\text { Provision of } \\
\text { emergency } \\
\text { contraception }\end{array}$} & Total \\
\hline \multirow{3}{*}{$\begin{array}{l}\text { Age category of } \\
\text { sexual assault }\end{array}$} & $\leq 5$ years & Yes & No & \\
survivors & $6-10$ years & $1(5.9 \%)$ & $6(7.3 \%)$ & $6(6.1 \%)$ \\
& $11-15$ years & $9(52.9 \%)$ & $14(17.1 \%)$ & $15(15.2 \%)$ \\
& $16-20$ years & $7(41.2 \%)$ & $27(32.9 \%)$ & $36(36.4 \%)$ \\
& $\geq 21$ years & $0(0.0 \%)$ & $33(40.2 \%)$ & $40(40.4 \%)$ \\
\hline \multicolumn{2}{r}{ Total } & $17(100.0 \%)$ & $2(2.4 \%)$ & $2(2.0 \%)$ \\
\hline
\end{tabular}

Concerning legal measures taken against perpetrators, $78(78.8 \%)$ were under investigation, and for $8(8.1 \%)$ of the survivors, there was no information at the time of evaluation. Medicolegal certificate of survivors was given to the police in $78(78.8 \%)$ but not for the remaining 5 $(5.1 \%)$ of the cases (Table 4$)$.

\section{DISCUSSION}

Sexual assault is the most under-reported crime against individual integrity, sexual freedom and affects up to one third of women worldwide during their lifetime. Although determination of the actual magnitude of sexual assault from hospital based study is difficult, it is the only means by which assessment of the types of sexual assault, interventions provided and related complications are possible.
In this study, the majority of the survivors of sexual assault (57\%) were children of less than fifteen years of age and $6 \%$ were five years of age and below. All survivors were females, most were less educated and of low income. This finding is similar with studies done in Ethiopian hospitals and other African countries $(13,18,26)$. Children at this age group are vulnerable to sexual assault and other gender based violence because of the traditional gender norms that support male superiority and entitlement, social norms that tolerate or justify violence against women, weak community sanctions against perpetrators and the prevalence of poverty (16).

Most studies had shown that genital injuries were not common with sexual assault and it is not necessary to make the diagnosis based on this finding on physical examination. However, in our study, clinical presentation of survivors showed 
that $78(78.8 \%)$ were found to have experienced rape and $42(42.4 \%)$ were children of fifteen years or below which is similar with the findings of a study done in Uganda (20). Alcohol was used to control the survivors in $4 \%$ of the incidents which shows that alcohol is less commonly consumed as identified in this study during or before sexual assault compared to other studies where it is used in $50 \%(17,24)$.

Worldwide, sexual assault by a stranger is usually not common and rather it starts in a home setting, surrounding neighborhood, school and working environment. This is true in our study, where the majority of the assailants were known to the survivors, 76 (76.8\%), assault committed in assailant's or survivor's home, $56(56.5 \%)$. This implies that most sexual assaults are committed by a person known to the survivors and there may be some degree of intimacy $(8,18,19)$.

Research on sexual assault against women shows an increased risk of current physical or sexual violence against women of a younger age, especially those aged 15 to 19 , living in single parent households and grandparent headed households (17). In our study, however, 69 $(69.7 \%)$ of the survivors were living with their biological mothers and fathers and were aged fifteen years and below. This implies that, in Ethiopian, the mere presence of mother and father will not safeguard children and family from sexual assault as debate or dialogue on sexuality is not a custom especially in rural areas and other factors like poverty and illiteracy in the family may contribute to sexual assault.

Previous study showed that most survivors were assaulted once by one assailant while a case of gang rape and assault on several occasions were reported rarely. In the current study, ninety-one percent of the survivors were assaulted by one assailant and $5(5.1 \%)$ encountered gang rapes. Seventy percent of the survivors were assaulted once while $8(8.1 \%)$ were assaulted for four and more episodes. This finding is similar with the finding of a study done in Kampala (18).

Police station was the first institution to which the crime of sexual assault was reported in $75(75.8 \%)$ of the cases, and $48(48.5 \%)$ of the affected were taken to the hospital by their family, while $40(40.5 \%)$ were taken by police. This reflects the widespread belief that sexual assault is primarily considered as a crime rather than a health concern, and as a result, there are delays in important health interventions aimed at preventing complications arising from sexual assault (22).

Most health care interventions can only be delivered when the survivors present in the first one to five days of sexual assault to prevent complications. However, studies in developing countries have shown that this effective widow for intervention is usually delayed by 18.4 days (17), compared to the median time from onset of assault to presentation of 16 hours in USA. Similarly, in our study, the interval between the incident of sexual assault and first presentation to the hospital ranges from 1 day to 240 days with the mean time of 15 days. Among the reasons for delays in seeking care in the Ethiopian contexts were reported to be: threat from the assailant, financial constraints, abduction, and the lack of services in the nearby health facility (14).

Genital and non-genital injuries are immediate complications of sexual assault which sometimes may be life threatening and need immediate medical care. In this study, $80(80.8 \%)$ of the assaulted had genital lesions of which hymenal tear accounts for $75(75.8 \%)$, perineal tear for $3(3.0 \%)$, and rectovaginal fistula for 1 $(1.0 \%)$. In addition, $18(18 \%)$ of those with hymenal tear had associated non-genital lesions, and of these, one had sustained right humeral shaft fracture. Twenty seven percent had associated mild to severe non-genital lesions and 13 (13\%) had neither genital nor non-genital lesions. This finding is similar with the study done in Kampala (18).

Survivors of sexual assault are vulnerable to a number of sexual and reproductive health problems, particularly unwanted pregnancy, HIV infection and sexually transmitted infections (STIs). Because of this fact, screening tests are crucial for all survivors of sexual assault for STIs and HIV infection and pregnancy when they are believed to be in the reproductive age or developing secondary sexual characteristics (23, 24). In our study, all the survivors believed to be in the reproductive age $79(79.8 \%)$, except 3 survivors, had pregnancy test and $13(17.1 \%)$ them were pregnant at the time of evaluation. When compared with previous studies done in Addis Ababa, this is much higher possibly because people in Addis and around might have had better awareness about the complications of sexual 
assault and sought care relatively earlier (14). Ninety-nine percent of the survivors had HIV test and $5(5.1 \%)$ were positive at the time of evaluation. All HIV infected survivors were children under fifteen years of age. The vulnerability to HIV infection in this age group may be explained by the high chance of genital injury which will increase the chance of acquisition of infections. From this, one can understand that sexual assault is a major contributor to child HIV infection in our setting. Ninety-three percent of the survivors were screened for one or more STIs other than HIV and 13(14.1\%) were positive.

Although $42(77.8 \%)$ of the survivors of sexual assault were potentially eligible for emergency contraception (EC) at the time of presentation, only $17(40.5 \%)$ received the service from the hospital staff. This is higher than the figure reported from a study in Ethiopia (14) and similar with a study done in Zambia (22). In addition, sixty point five percent of the survivors presented within three days were provided with post exposure prophylaxis (PEP) for HIV, two third of those presented within 24 hours were provided with STIs prophylaxis and 91 (91.9\%) were given counseling, though not a formal counseling (27). These findings are lower for counseling, provision of EC, and prophylaxis for STIs when compared with the findings of a study done in Kampala (18), and similar for HIV post exposure prophylaxis with a study done in Zambia (22). This shows that there is a huge gap in providing care for survivors of sexual assault from the health provider.

Provision of medico-legal certificate containing the result of forensic examination, specimen collection, analysis and documentation provide a vital link between the health and the criminal justice systems, and is a crucial component in securing prosecution and sentencing $(24,28)$. In our study, concerning legal measures taken against perpetrators, $78(78.8 \%)$ of the incidents were reported and were under investigation, and, for $8(8.1 \%)$ of survivors, there was no information at the time of evaluation. Thirteen percent reported pending trial or denial of justice. Medico-legal certificates of survivors were given to the police in $78(78.8 \%)$ but not given in $5(5.1 \%)$ of the cases. This shows that there is a gap in the justice system in protecting women against this crime.

In conclusion, in this study, all sexual assault survivors were females, the majority were children under fifteen years $(57.5 \%)$, less educated and from rural areas (68.7\%). The most common type of sexual assault was rape; genital injury was hymenal tear and alcohol was rarely used prior to or during sexual assault. In the majority, the survivors were assaulted during the day; the assailants were known to the survivors; the assailants were assaulted once by one assailant; cases were reported first to the police and there was a delay in reporting to health institutions (mean of 15 days). Although screening tests were offered for survivors, there was a huge missed opportunity with respect to provision of EC, PEP for HIV and prophylaxis for STIs which might have resulted in related sexual and reproductive health problems which possibly could have been averted.

Therefore, awareness creation of the community about sexual assault and related complications will help survivors to present earlier to health institution and prevent complications by obtaining the packages of care for sexual assault survivors. Health professionals should pay special attention to providing screening and packages of care. In addition, the sexual and reproductive health right of women and right of children survivors of sexual assault should be strengthened from the side of policy makers and should be enacted accordingly by government bodies and community to protect individuals.

\section{ACKNOWLEDGEMENTS}

We would like to acknowledge the study participants for providing the necessary information and the data collectors for collecting data. We are grateful to W/o Yetinayet Ashine for typing the manuscript and Jimma University for its financial and logistic support.

\section{REFERENCES}

1. Joyce Lukima. U.S. National Sexual Violence Resource Center. Mar 2009. 
2. Population council. Sexual and gender based violence in Africa: Literature review. Feb 2008.

3. Berek, Jonathan S. Berek \& Novak's Gynecology. $14^{\text {th }}$ eds, Lippincott Williams \& Wilkins; 2007.

4. Carlos Tadayuki, Oshikata, Aloíso José Bedone, et al. Characteristics of women victims of sexual violence and their compliance with outpatient follow-up: time trends at a referral center in Campinas, São Paulo State, Brazil. Cad. Saúde Pública, Rio de Janeiro, 2011; 27(4):701-13.

5. Jewkes, R, Sen P, García-Moreno C. "Sexual violence". In: E. G. Krug et al. (Eds.) World report on violence and health. Geneva, Switzerland: World Health Organization, 2002.

6. UNIFEM. Violence against women. UNIFEM, 2009. Website: http://www.unifem.org/gender_issues/violenc e_against_women/ (Accessed August, 2009).

7. Kristin L. Dunkle, Rache K. Jewkes, Heather C. Brown, et al. Prevalence and Patterns of Gender-based Violence and Revictimization among Women Attending Antenatal Clinics in Soweto, South Africa. Am J Epidemiol, 2004; 160:230-39.

8. Mugawe, D, A. Powell. Born to High Risk: Violence against Girls in Africa. The African Child Policy Forum, 2006.

9. Helen Luce, Sarina Schrager, Valerie Gilchrist. Sexual assault of women. American Family Physician February, 2010; 81(4): 48995.

10. Jewkes, R. "Intimate partner violence: Causes and prevention". The Lancet, 2002; 359:142329.

11. WHO. WHO Multi-country Study on Women's Health and Domestic Violence against Women: summary report of initial results on prevalence, health outcomes and women's responses. Geneva, World Health Organization, 2005a.

12. Claudia G-M, Henrica AFM J, Mary E, Lori $\mathrm{H}$, Charlotte $\mathrm{H} \mathrm{W}$. Prevalence of intimate partner violence: findings from the WHO multi-country study on women's health and domestic violence. The Lancet, 2006; 368: 1260-69.
13. Z. Lakew. Alleged cases of sexual assault reported to two Addis Ababa Hospitals. East African Medical Journal, 2001; 78(2): 80-83.

14. Feleke W, Ahmed A. Emergency contraception provision for sexually assaulted women at health facilities in Addis Ababa, Ethiopia. Ethiopian Journal of Reproductive Health May, 2009; 3 (supp1):52-58.

15. McCall-Hosenfeld, Karen M. Freund, Jane M. Liebschutz. Factors associated with sexual assault and time to presentation. Prev Med. June, 2009; 48(6): 593-595.

16. Krug, Etienne, Linda Dalhberg, James Mercy, Anthony Zwi, Rafael Lozano. World Report on Violence and Health. Geneva: WHO Eds, 2002.

17. Kishor, S. \& K. Johnson. Profiling Domestic Violence - A Multi-Country Study. Calverton, Maryland: ORC Macro, 2004.

18. Samuel O, Julius W, Paul K, Robert B. Clinical presentation and management of alleged sexually assaulted females at Mulago hospital, Kampala, Uganda. African Health Sciences 2005; 5(1): 50-54.

19. S Cox, G Andrade, D Lungelow, W Schloetelburg, $\mathrm{H}$ Rode. The child rape epidemic: Assessing the incidence at Red Cross Hospital, Cape Town, and establishing the need for a new national protocol. $S$ Afr Med J, 2007; 97: 950-55.

20. Campbell R, Dworkin E, Cabral G. An Ecological Model of the Impact of Sexual Assault on Women's Mental Health. Trauma Violence Abuse, 2009; 10: 225-246.

21. WHO. Mental Health Aspects of Women's Reproductive Health: A Global Review of the Literature. Geneva: WHO; 2009.

22. ECAfrique. EC and care for sexual assault. ECAfrique bulletin, May 2004; 22.

23. WHO. Protocols for the medical management of persons who experienced sexual violence. Geneva: WHO; 2003b.

24. FMOH. National guideline for the management of survivors of sexual assault in Ethiopia. Nov 2009.

25. Speight C.G. Piloting post-exposure prophylaxis in Kenya raises specific concerns for the management of childhood rape. Transactions of the Royal Society of Tropical Medicine and Hygiene, 2006; 100:14-18. 
26. BL Meel. Incidence of HIV infection at the time of incident reporting, in victims of sexual assault, between 2000 and 2004, in Transkei, Eastern Cape, South Africa. African Health Sciences, 2005; 5(3):207-12.

27. Campbell R, T. Sefl. "The Impact of Rape on Women's Sexual Health Risk Behaviors". Health Psychology, 2004; 23(1):67-74.
28. Kenya Ministry of Health. National Guidelines on the Medical Management of Rape/Sexual Violence. 1st edition, Nairobi, Kenya, Tonaz Agencies; 2004. 